\title{
Seafaring simulations and the origin of prehistoric settlers to Madagascar
}

\author{
Scott M. Fitzpatrick \\ Department of Sociology and Anthropology, North Carolina State University, USA \\ scott_fitzpatrick@ncsu.edu
}

Richard Callaghan

Department of Archaeology, University of Calgary, Canada

\section{Introduction}

How and when islands in the Pacific and Indian Oceans were colonised by Austronesian speakers has been of great interest to archaeologists for decades. Few people, however, have gone to such great lengths to answer the questions from so many different methodological and theoretical perspectives as Atholl Anderson. Atholl probably also has the distinction of having stepped on more islands in the Pacific than any other archaeologist and his efforts to understand Oceanic prehistory have influenced and will continue to inspire future generations of archaeologists. Given that his research has been so varied and spanned several oceans, dozens of islands and thousands of years in prehistory, we felt it appropriate to write a paper for Atholl's festschrift that embodied one of the core questions regarding Austronesian expansion - how did peoples reach these islands?

Using computer simulations of voyaging, we examine the prehistoric colonisation of Madagascar. This approach to studying ancient seafaring is increasingly used worldwide to investigate colonisation, migration and culture contact (Levison et al. 1973; Irwin 1992; Callaghan 2001, 2003a, 2003b, 2003c; Montenegro et al. 2006; Avis et al. 2007; Callaghan and Fitzpatrick 2007, 2008). The results of these simulations can be coupled with other data to develop more robust hypotheses regarding the possible routes of migration to Madagascar by Austronesian speakers, illustrating the extent to which peoples were willing to travel to colonise new islands.

\section{The colonisation of Madagascar}

Madagascar, one of the world's largest islands $\left(587,000 \mathrm{~km}^{2}\right)$, is located in the Indian Ocean about $420 \mathrm{~km}$ from the southeast African coast and $5600 \mathrm{~km}$ west of the Indonesian archipelago. 
Archaeological and paleoenvironmental evidence suggests Madagascar was first colonised by peoples about 2000 BP (Dewar and Wright 1993), although its settlement history thereafter appears to have been more complex, with people voyaging from around the Indian Ocean, including Southeast Asia, East Africa, South Asia and the Near East (Dewar and Wright 1993:418). What makes the Madagascar case particularly intriguing is that it lies relatively close to the African mainland, but was settled initially by Austronesian speakers from much further away. The most widely spoken language on the island is Malagasy, of Austronesian origin, which has its closest affinity to Borneo (Dhal 1951, 1977). There is also evidence of extended contact with the Bantu language, but it seems to have diverged from Island Southeast Asian languages 1000 to 2000 years ago (Dewar and Wright 1993:419). Genetic analysis also indicates major migrations to Madagascar from both Indonesia and East Africa (Pigache 1970).

\section{A computer-simulated approach}

Migrations from East Africa would have required sea crossings of about $400 \mathrm{~km}$ (215 nautical miles). Direct migrations crossing the Indian Ocean from Indonesia to Madagascar, however, were 15 times further, requiring sea crossings of about $6000 \mathrm{~km}$ (3200 nautical miles). It is the latter crossings which are of interest here, since this is where the first colonists originated. In this paper, we use computer simulations to investigate migration routes, strategies and seasonality. These simulations take advantage of detailed oceanographic, anemological and climatological data to determine how watercraft will move or react to ocean conditions at a given time of the year.

A number of voyaging strategies can be investigated using computer simulations. The two basic divisions are between simple downwind sailing and directed voyages. In this analysis, we investigate both strategies. The first is downwind sailing, or sailing before the wind. In this strategy, vessels are simply sailed before the wind with little or no attempt to navigate in a particular direction. This allows close to the maximum distance to be covered in a given time. The initial discovery of Madagascar may have involved this type of strategy. It is consistent with, but not limited to, situations where sailors are lost at sea. Dening (1963:138-153) notes that the limited empirical evidence of voyagers lost at sea in Polynesia suggests a common pattern of behaviour in which sailors conclude they are lost early in the voyage and respond by allowing the vessel to sail before the wind, with no further attempt to navigate in a particular direction.

The second strategy used in the simulations is one in which sailors intentionally try to sail in a particular direction. This requires vessels that have some capability to sail to windward. During the period from 1000 to 2000 years ago, it is well known that Indonesian and other vessels sailing in the Indian Ocean had such capabilities. McGrail (2001:301) notes that vessels carved into the eighth-ninth century temple of Borobudur on Java carry lug sails and canted rectangular sails. La Baron Bowen Jr (1954:201) refers to the canted rectangular sails at Borobudur as a form of lug sail. Lug sails are one of the most powerful rigs for sailing to windward that can be made using fairly simple technology (Bolger 1984:42). We also simulated return trips from Madagascar to Indonesia as linguistic evidence suggests contact was maintained between Malagasy speakers and languages on the eastern side of the Indian Ocean (Adalaar 1989).

One possible route is described in the Periplus of the Erythraean Sea (Schoff 1912). The Periplus was probably written about AD 60 (Schoff 1912:15) and overlaps the period of interest here. The Periplus describes the timing of trading voyages from about $10^{\circ} \mathrm{S}$ along the East African coast around the Indian Ocean and through the Straits of Malacca to about $5^{\circ} \mathrm{S}$ off the east coast of Sumatra. There is a description of the goods traded along what is largely a coastal 


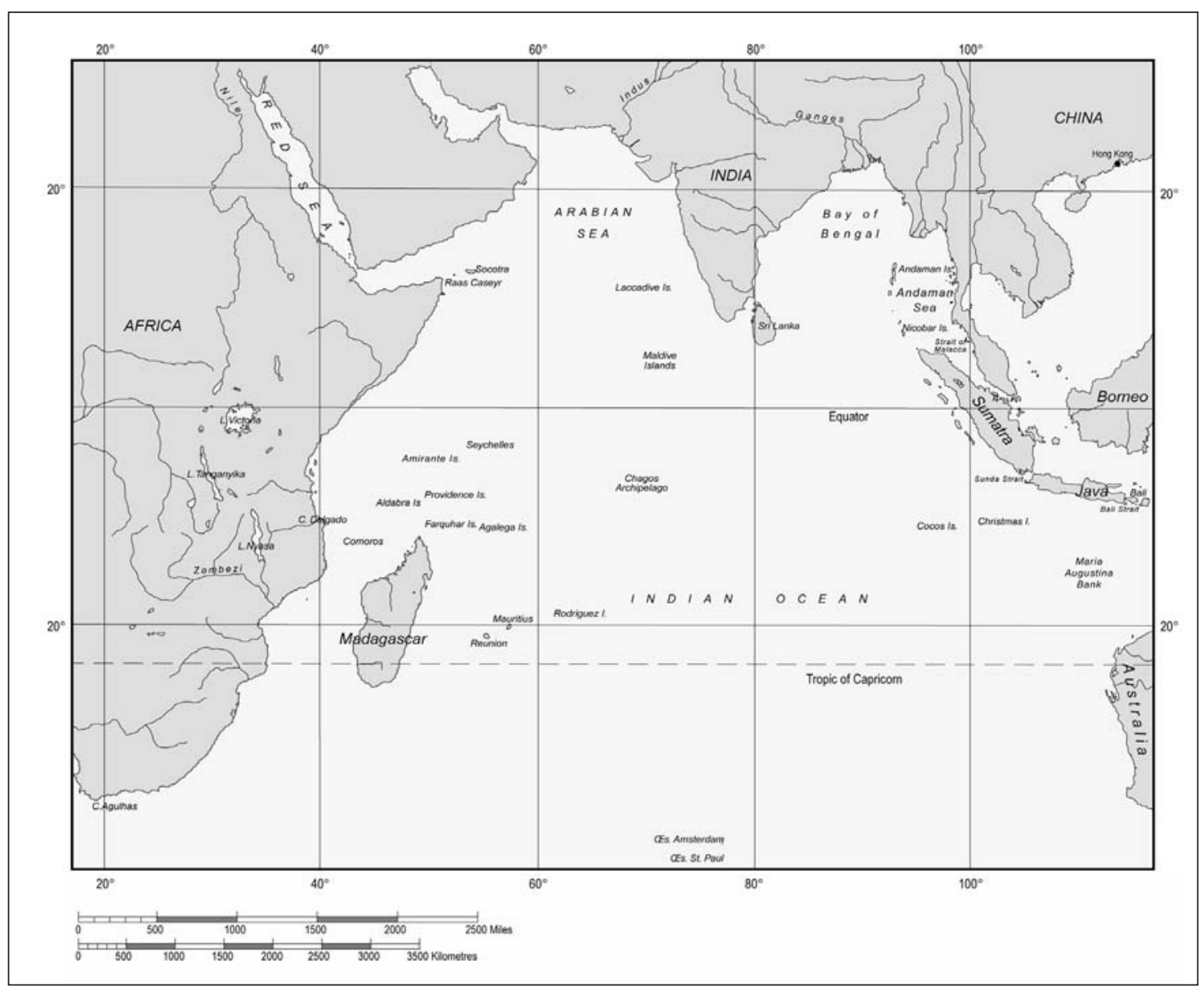

Figure 1. Map of the Indian Ocean.

route. However, seasons for two open-sea crossings are given. One is for crossing the Arabian Sea, and the other for crossing the Bay of Bengal. The crossings make use of the seasonal monsoonal shifts. Overall, the coastal route from the Straits of Malacca to just north of Madagascar would involve sailing more than $11,000 \mathrm{~km}$, or 6000 nautical miles. As this route is well documented and is primarily a coastal trading route, we did not simulate migration voyages along it. Rather, we investigate alternative, more direct routes to the south.

\section{The simulation program}

The problem of establishing alternative migration routes, durations and seasonality is addressed here using computer simulations based on the known patterns of winds and currents throughout the year. When running downwind-sailing simulations, four main variables are considered: (1) current patterns; (2) wind patterns; (3) vessel type; and (4) propulsion. The structure of the simulation is the actual mechanics of the program - for example, how data are selected, and success as a percentage of all voyages calculated. Parameters include such factors as the starting position of the vessel, whether it is a downwind or directed voyage, the duration at sea, and what constitutes a successful voyage.

Currents will affect objects caught in them in a 1:1 ratio. That is, the object will have the same speed and set as the current unless other forces are operating. Any object floating with an appreciable part above the water will be more affected by winds than currents unless a current is exceptionally strong. The effect of wind on objects floating high in the water was used by 
traditional navigators in Kiribati to determine the direction of land when recent winds differed from the flow of the current (Lewis 1972:212). The source of wind and current data is the CDROM version of the US Navy Marine Climatic Atlas of the World (Version 1.1 1995).

The type of vessel and how it is propelled make up the final variables of the problem, as the shape of an object above and below the waterline will respond to the effects of wind. However, in this problem, we do not know what types of vessels were used. Some form of Indonesian sailing vessel from the period of interest is most likely, as Indonesian-style outriggers are still used in some parts of Madagascar (Dewar and Wright 1993:419). Recently, a replica of a firstmillennium Indonesian vessel based on one depicted on the temple of Borobudur <http:// www.borobudurshipexpedition.com/index.htm> made a direct crossing of the Indian Ocean to Madagascar. However, there are 11 vessels depicted at Borobudur, not all of which are the same design (McGrail 2001:301). Because we do not know precisely what types of vessels were involved in migrations to Madagascar, and it is likely multiple designs were used, we have used generalised sailing speeds derived from a number of vessel types. Speeds at which the vessels used in this simulation can travel under various wind conditions are taken from figures provided by Levison et al. (1973).

The program itself is also based on the United States Navy Marine Climatic Atlas (US Navy 1995), which includes all of the world's seas and oceans, except Arctic waters. The data are organised in a resolution of one degree Marsden squares (one degree of longitude by one degree of latitude). In particular, this resolution allows the effects of smaller and more variable currents to be accurately reflected in the outcomes. The program randomly selects wind and current data that are frequency-weighted according to the compiled observations of the Marine Climatic Atlas. These forces are allowed to operate on vessels for a 24-hour period before a new selection is made (see Levison et al. 1973 for a justification of the period length).

The distance and direction travelled are based on the wind and current data, combined with the speeds from Levison et al. (1973:19) and parameters selected by the program operator. Examples of parameters here include the use of sails, sea anchors to keep a vessel oriented into the wind during storms, or droques to slow the vessel and prevent following seas from swamping it. It is also possible to include changes of heading when under sail. This last feature is important when assessing the level of navigational skill required to reach a selected target during directed voyages. The program automatically shifts to the database for the following month after the month originally selected has expired. This feature better reflects the reality of changing wind and current conditions over long voyages. The result of the simulations is expressed as the percentage of successes for a particular vessel type from selected points.

Parameters of the simulation are choices made by the program operator in order to set up the simulation to answer a particular question. These include the following information: (1) points of origin and destination; (2) crew strategy; (3) performance characteristics; (4) duration of voyages; (5) time of year; and (6) number of simulations.

Four points of origin were used, with Madagascar as the destination. These were the Bali Straits between Bali and Java; the Sunda Straits between Java and Sumatra; the north end of the Malacca Straits off the northwestern tip of Sumatra; and just west of Sri Lanka and south of India. One point of origin off the northeastern tip of Madagascar was used for return voyages to Indonesia.

The second parameter is the strategy used by the crew. As noted above, in this analysis, we have chosen to investigate two strategies. The first is downwind sailing or sailing before the wind. In this strategy, vessels are simply sailed before the wind with no attempt to navigate, 
allowing close to the maximum distance to be covered in a given time. The second strategy is one in which sailors intentionally try to sail in a particular direction.

The duration of the downwind voyages was set at 200 days, after which it was assumed the crew perished. Two hundred days would approach the longest voyage in an open boat due to shipwreck or other misfortunes documented in the Pacific (Howay 1944; Levison et al. 1973:20-21; Callaghan 2003c). The longest recorded shipwreck voyage in an open boat seems to be in the order of seven to eight months, and several of these have been documented in the past few decades. A number of these recorded voyages covered distances of about $5500 \mathrm{~km}$ over six to 10 weeks, and more travelled slightly shorter distances. For the purposes of this study, 100 downwind voyages were simulated for all 12 months of the year from each of the points of origin.

\section{Survival}

Survival of the crew in long open-ocean voyages is an important consideration. The three main factors affecting survival at sea are the surface temperature, the availability of water and the availability of food. These factors are all related to the duration of the voyage. Sea surface temperature is not a significant factor here, as the surface temperatures of the equatorial Indian Ocean, 28C-29C (Heikell 1999:209), are well above temperatures that would present a significant problem (McCance et al. 1956).

Water is probably the greatest problem on long ocean voyages. Lee $(1965: 96,99)$ states that the maximum time an individual can be deprived of water under survival conditions is 10 days. The availability of water, however, is very difficult to calculate. As stated by Levison et al. (1973:20), 'between the extremes of no water and ample water the whole range of unpredictable situations makes it impractical to construct a separate risk table for this factor' in a simulation program. Aside from what is stored on board, water can be obtained from precipitation, especially in the tropics, and it is not difficult to retrieve from sails (Heikell 1999:5). Even in the dry season, some regions of the Indian Ocean have showers in the afternoon (1999:214-215). There are several other sources of drinking water at sea, besides precipitation. Bombard (1986:61) was, at times, able to collect nearly a pint of water from dew during survival experiments in the Mediterranean. While displacement vessels have an advantage over rafts in that the hull will collect dew, almost any material (including cloth, matting and leather) can be used to collect water particles. Lee and Lee (1980:139-160) cite instances in which water has been obtained by shipwreck survivors from fish and barnacles, or in which blood was a viable substitute. Bombard (1986:212-213) demonstrated that one can survive by drinking seawater, as long as small amounts are drunk before dehydration sets in.

Given that the voyages investigated here are not shipwreck situations, it is expected that vessels are well provisioned. A wide variety of dried fruits and nuts are available in the lands around the Indian Ocean (Heikell 1999:11) and rice and other grains have considerable storability. Fish are currently abundant and easy to catch in the equatorial Indian Ocean (Heikell 1999:18) and should have been more so in the past. In emergencies, a number of resources may have been available. Lee and Lee (1980:139-160) describe instances of survivors eating everything from non-vegetable plankton to toredo borers. One report (Lee and Lee 1980:110-111) describes barracuda leaping on to a life-raft, though they were perceived more as a threat than a food source. Sharks, often too small to be a threat, are commonly reported following small vessels. Turtles and sea birds are other food sources not necessarily requiring specialised technology to capture that are often reported available to survivors. 


\section{Results}

Downwind sailing from the Bali Straits would not allow voyagers to reach Madagascar at any time of the year. However, from April to August, it would be possible with some knowledge to use the technique to sail significant distances to the west and to reach $88^{\circ} \mathrm{E}$, particularly in June. Similarly, downwind sailing is not a feasible strategy for reaching Madagascar from the Sunda Straits. From the Bali Straits, significant progress westward can be made from April to August, especially in June when voyagers using downwind sailing could reach as far west as about $83^{\circ} \mathrm{E}$.

From the northwest tip of Sumatra, downwind sailing could allow voyagers to reach as far west as about $72^{\circ} \mathrm{E}$ from December to March, before they would be driven back to the east. However, in November and December, downwind sailing could be used to reach Sri Lanka in as few as 40 days, making no attempt to navigate other than keeping the wind at the stern. From the India/Sri Lanka position in January (Figure 2), and to a lesser extent in February, the pattern for downwind sailing is interesting. Vessels would move to the southwest through the Maldives before the pattern bifurcates, with vessels moving either to Madagascar or Java. Downwind voyages to Madagascar using this route would take as few as 81 days. The route to Java could take as few as 73 days. In March, November and December, vessels move through the Maldives before travelling east to Indonesia. During the rest of the year, vessels are pushed back to Sri Lanka.

The final set of downwind simulations was from Madagascar to Indonesia. From August through April, most vessels were simply blown back to the island, with a few in March and April, and August through December moving to the west, and landing on the adjacent African coast. The majority of vessels setting sail from May to July moved to the northwest, landing along the Somali coast, with a smaller number reaching the west coasts of India and Sri Lanka.

The second set of simulations assumed a moderate ability to sail to windward, averaging 1 knot when sailing across or into the wind. These voyages were directed, in that a heading towards Madagascar was selected. Other than choosing an initial heading, no attempt was made to steer the vessels. From the Bali Straits, it was not possible to reach Madagascar. From August to March and in May, vessels were forced to Java. In June and July, vessels could sail west to a position south of Sri Lanka before being forced back to the east. However, 18 percent of vessels setting out in April reached Sri Lanka in an average of 157 days.

Sailing west from the Sunda Straits from December through March, a number of voyages either reached Madagascar or passed north of the island. Vessels passing north would have had little trouble making landfall on Madagascar. In December, five percent of vessels passed to the north of Madagascar, reaching Africa in 103 to 115 days. In January, eight percent of vessels reached Madagascar or the nearby Seychelles or Amirante Islands. On average, the voyages took 163 days, but they could be as short as 109 days. In February, 18 percent of vessels landed in Madagascar or the Seychelles and Amirante Islands. On average, the voyages took 142 days, with a minimum of 99 days. Vessels starting out in March (Figure 3) had the greatest chance of reaching Madagascar, or they passed to the north, landing on the coast of Africa in a total of 53 percent of voyages. The average voyage duration was 152 days, with the shortest being 100 days. In April and October, vessels made headway south of Sri Lanka before being swept eastward. Approximately 25 percent of vessels landed on Sri Lanka and the west coast of India. From May to September, vessels sailed west to a position south of Sri Lanka before being blown back eastward to the coasts of Thailand and Burma. Vessels setting sail in November primarily were forced back to Java, although two landed on Sri Lanka and two on the Somali coast.

Simulations of voyages westward from the northwest tip of Sumatra in January (Figure 4) 


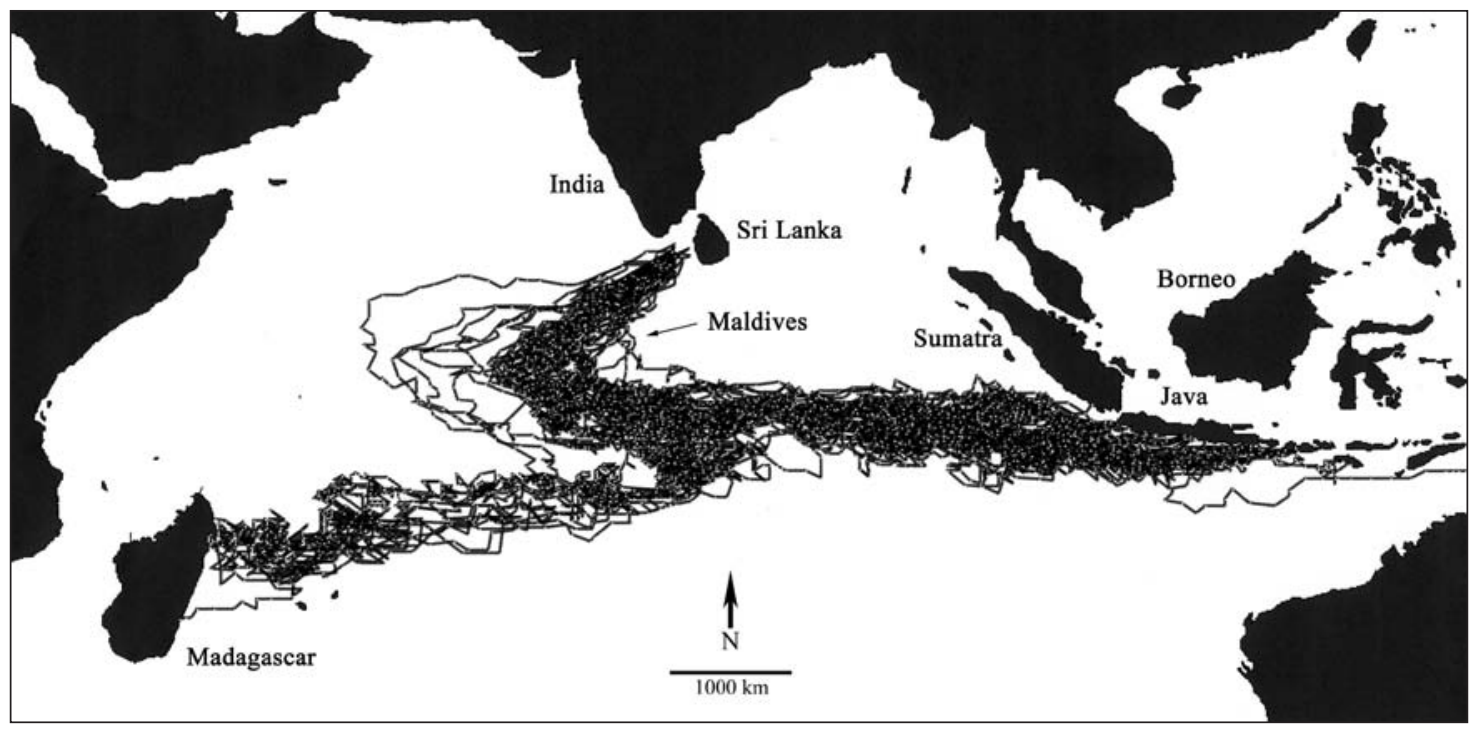

Figure 2. Downwind sailing from South India/Sri Lanka in January.

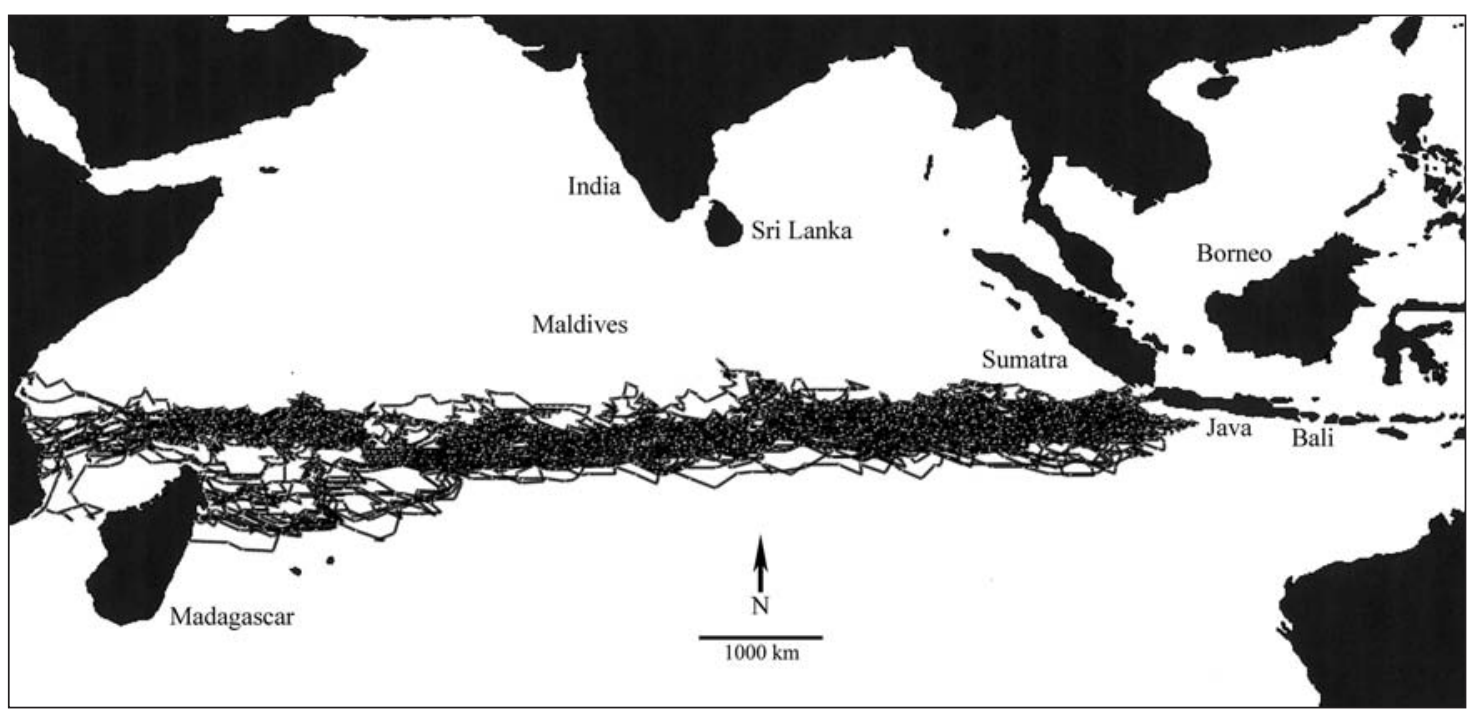

Figure 3. Directed sailing from the Sunda Straits in March.

and February all reached Madagascar in 93 and 72 days respectively. In December and March, a few vessels reached Madagascar, but most passed to the north, landing on the African coast. Vessels starting in December reached Madagascar in a minimum of 111 days, while those beginning in March took a minimum of 180 days. Vessels starting in October were forced to the west coast of India in a minimum of 40 days, while vessels starting in November were mostly forced to Sri Lanka in a minimum of 21 days. In April, vessels were all forced to Sri Lanka in a minimum of 23 days.

Simulations from the India/Sri Lanka position were given a southwest heading. From December through March, all voyages passed through the Maldives, making landfall on Madagascar. The minimum durations were as follows: December: 60 days; January: 44 days; February: 43 days; March: 61 days. Vessels in April were first swept towards Sumatra and then to the west past northern Madagascar, landing on the African coast in a minimum of 110 days. A similar pattern was found for October, with vessels landing on the Somali coast in minimum of 95 days. 
The final set of simulations was from Madagascar to Indonesia. A heading of due east was given to the vessels. From November through April, there were successful voyages between Madagascar and Indonesia. However, the percentage of successful voyages and their durations varied considerably. Success ranged from 50 percent for vessels setting out in March, to 100 percent for those setting out in April. Durations ranged from 113 days in January, to 55 days in November. Overall, April (Figure 5) proved the most favourable time to begin voyages to Indonesia, with 100 percent success rates and durations as low as 63 days. In May, most vessels landed in Sri Lanka, with a minimum duration of 38 days. From May through August, most vessels landed on the west coast of India and Sri Lanka. Minimal durations were from 23 to 38 days. In September, about half of the vessels landed in India and Sri Lanka, with a minimum duration of 29 days, while the rest landed on the east coast of Africa. In October, virtually all vessels were swept west to Africa.

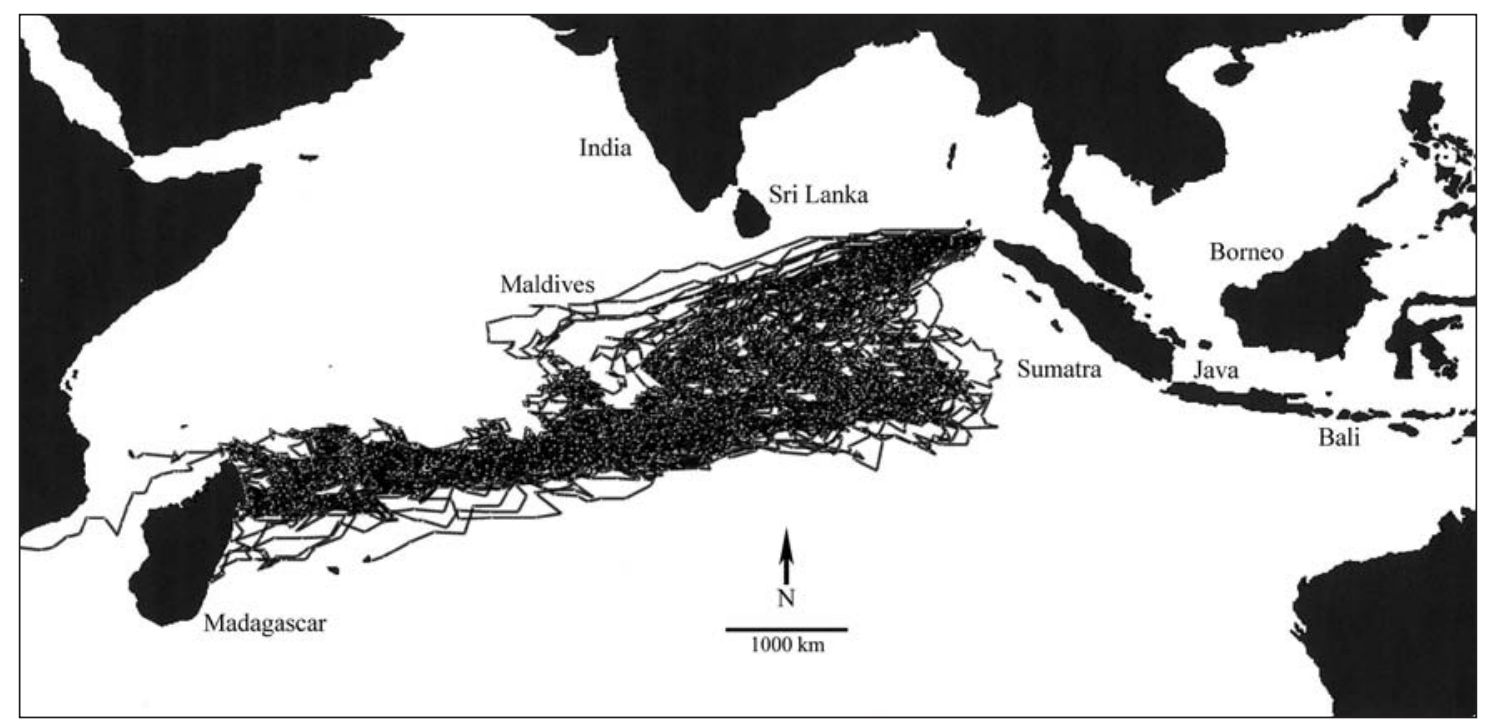

Figure 4. Directed sailing from northwest Sumatra in January.

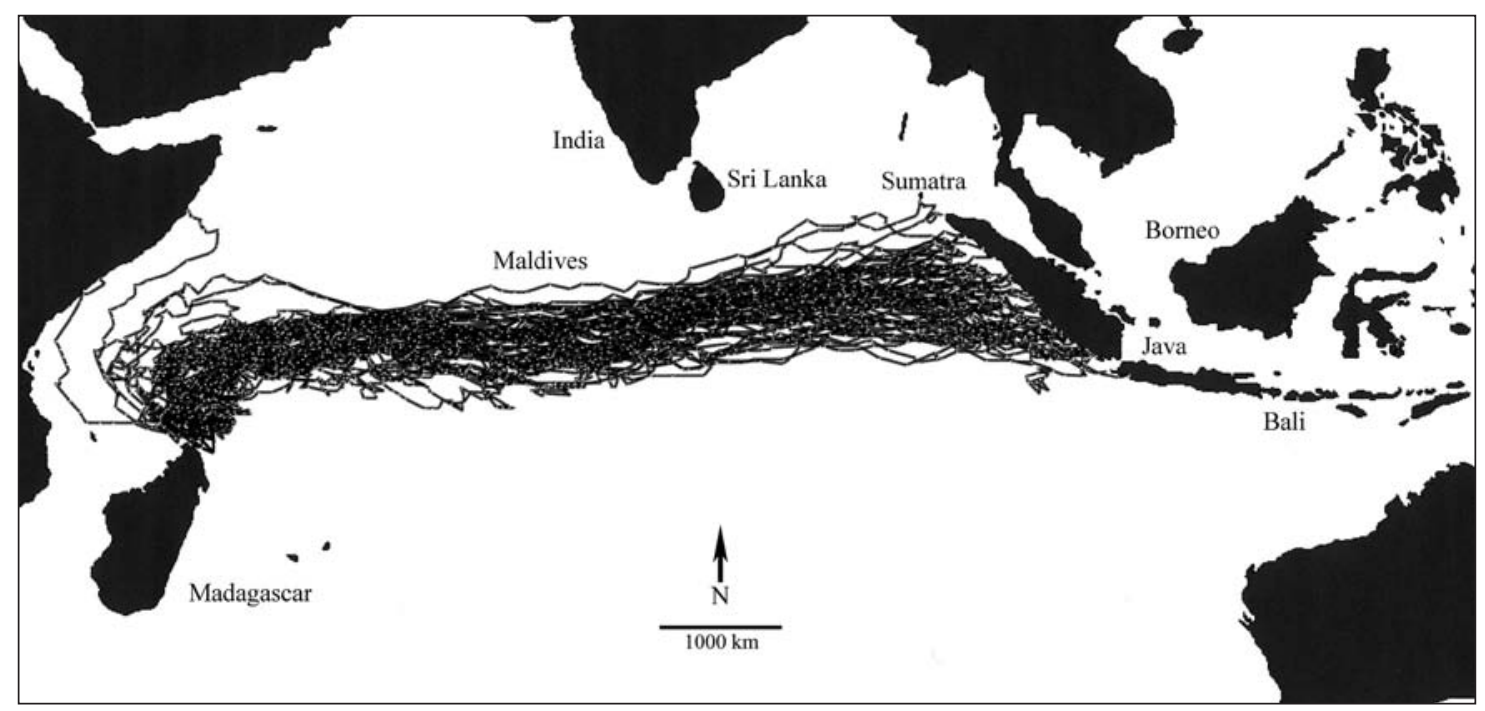

Figure 5. Directed sailing from Madagascar to Indonesia in April. 


\section{Discussion and conclusions}

Computer simulations of seafaring between Indonesia and Madagascar have provided insight into the challenges facing prehistoric settlers. Our findings indicate that downwind sailing from the Bali or Sunda Straits did not result in reaching Madagascar. Some vessels would have made it as far to the west as $88^{\circ}$ E from the Bali Straits and $83^{\circ}$ E from the Sunda Straits during the months of April through August. After reaching those positions, vessels are forced back to Indonesia. Using a downwind strategy from these positions does not result in the discovery of any islands. Downwind sailing from off the northwest tip of Sumatra proves more intriguing. From December through March, vessels could reach as far west as $72^{\circ} \mathrm{E}$ before being swept back to the east. The ability to sail this far to the west would bring vessels to the Maldives and the Chagos Archipelago. In the months of November and December, downwind sailing could bring vessels from off Sumatra to Sri Lanka in about 40 days. Downwind sailing from the India/ Sri Lanka position is also interesting, particularly in January, when vessels pass through the Maldives before sailing on to either Madagascar or Indonesia. At other times of the year, vessels also pass through the Maldives, but only move to Indonesia.

The pattern of downwind simulations suggests the Maldives, and to a lesser extent the Chagos Archipelago, may have been important stopping points on the voyage to Madagascar from either the India/Sri Lanka or Sumatra positions. They may also have been important for travel from India/Sri Lanka to Indonesia. The Maldives and the Chagos Archipelago are not well known archaeologically, however. Although Maldivians were aware of the Chagos Archipelago (Ramiro-Frias 1999:19), the archipelago was not permanently settled until the French arrived in the second half of the 18th century. According to Maloney (1980:75), Buddhists arrived in the Maldives in the first few centuries AD. The islands were occupied at the time (1980:49-70), but the antiquity of occupation has not yet been determined. That the Maldivians were capable sailors at the time of the initial settlement of Madagascar from Indonesia is suggested by the record of Ammianus Marcellinus (1980:72) writing in the fourth century AD, who provides a list of emissaries sent to Rome, including Maldivians.

People voyaging from Indonesia to Madagascar by simply using a strategy of downwind sailing and starting from December to March could have broken the journey in the Maldives. There, they could have resupplied and provisioned, and sailed to a favourable position for continuing on to Madagascar, particularly in January. However, there does appear to have been two-way contact between the two regions. Downwind sailing from Madagascar to Indonesia is not possible at any time of the year, nor can the Maldives be reached. From May to July, it would have been possible to use the route described in the Periplus of the Erythraean Sea to travel along the African coast and then on to southern India and Sri Lanka, and from there to Indonesia.

Sailing with a heading towards Madagascar, and with the ability to sail across and to windward, is more complex. From a position in the Bali Straits, some vessels could make it to the Maldives in June and July, but the numbers are too low to make this a viable route for regular contact. A fairly large number of vessels would reach Sri Lanka if starting out in April, but the durations would be rather long. March would be the most favourable month for westward sailing to Madagascar. While just over half of the vessels were successful in the simulations, the numbers would be much greater if the Maldives were used as a waypoint. As with sailing from the Bali Straits seasonally, a significant number of vessels would have landed in Sri Lanka. Vessels starting out during January and February from off the northwest tip of Sumatra would all arrive in Madagascar, most in a reasonable length of time. The Maldives would once again be strategic in the voyages. As with the other Indonesian starting points, a significant number of 
vessels made landfall in Sri Lanka in the simulations. From December through March, vessels simply heading to the southwest from Sri Lanka would reach Madagascar via the Maldives in a fairly reasonable length of time. Sailing from Madagascar to Indonesia with an eastward heading is possible from December through April. The April success rate is 100 percent. The Maldives are also strategic to these voyages.

Durations for the simulations with a heading are considerably longer than is likely in reality. Only a single heading was chosen and maintained throughout the voyages. Sailors would have had the flexibility to change their heading throughout the voyage, moving out of areas with unfavourable winds and considerably shortening the duration of the voyage. Still, the patterns shown by the simulations do reveal the possibilities for direct contact between Indonesia and Madagascar. They also show the interconnectedness of sea routes in the Indian Ocean.

Simple downwind sailing could account for westward voyages from the northwest tip of Sumatra if the voyages were begun in November and December, but such voyages would have required use of the Maldives as a waypoint. The voyages would be lengthy, with a large number of failures. Unsuccessful voyages would not necessarily be disastrous for the crews, as most vessels would end up back in Indonesia or in Sri Lanka. The strategy of using downwind sailing to reach Madagascar from Indonesia seems unlikely, even using the Maldives as a stopping point. Downwind voyages from Madagascar are ruled out to Indonesia, but not to western India and Sri Lanka. In both instances, downwind sailing would need to follow a primarily coastal route, similar to that of the Periplus of the Erythraean Sea. Downwind sailing to either Madagascar or Indonesia from Sri Lanka in January and February is an interesting possibility, but the durations are rather long. The Maldives would again figure prominently in such voyages. Sailing on a westward heading from Indonesia would be most successful from off the northwestern tip of Sumatra starting in January and February, with most vessels passing through the Maldives. From the India/Sri Lanka position, with a southwest heading, starting in December through March, success in reaching Madagascar is high, and also would involve the Maldives. If leaving Madagascar in April with an eastward heading, the success rate for reaching Indonesia is 100 percent. Once again, the Maldives would be encountered.

In conclusion, if the weather patterns were followed, direct contact from northern Indonesia with Madagascar, and in the reverse direction, is feasible. However, it seems likely the Maldives, in such a strategic position, would have been relied on for resupplying and waiting for favourable conditions to continue the voyage. It might be expected that evidence of these stopovers will be found archaeologically in the Maldives, particularly if these voyages were repeated over time.

\section{Acknowledgments}

We would like to thank the editors for inviting us to contribute a paper to this important volume. Thanks also to reviewers who provided useful comments and especially to Atholl who has helped inspire a new generation of archaeologists. 


\section{References}

Adalaar, K.A. 1989. Malay influence on Malagasy: linguistic and culture-historical implications. Oceanic Linguistics 28:1-46.

Avis, C., Á. Montenegro and A. Weaver 2007. The discovery of Western Oceania: a new perspective. Journal of Island and Coastal Archaeology 2:197-209.

Bolger, P.C. 1984. 100 Small Boat Rigs. Camden Maine: International Marine.

Bombard, A. 1986. The Bombard Story. London: Grafton Books.

Breen, C. and Lane, P.J. 2003. Archaeological approaches to East Africa's changing seascapes. World Archaeology 35:469-489.

Burney, D.A., L. Pigott Burney, L.R. Godfrey, W.L. Jungers, S.M. Goodman, H.T. Wright and A.J.T. Jull 2004. A chronology for late prehistoric Madagascar. Journal of Human Evolution 47:25-63.

Callaghan, R.T. 2001. Ceramic age seafaring and interaction potential in the Antilles: a computer simulation. Current Anthropology 42:11-22.

Callaghan, R.T. 2003a. Comments on the mainland origins of the Preceramic cultures of the Greater Antilles. Latin American Antiquity 14:323-338.

Callaghan, R.T. 2003b. Prehistoric trade between Ecuador and west Mexico: a computer simulation of coastal voyages. Antiquity 77:796-804.

Callaghan, R.T. 2003c. The use of simulation models to estimate frequency and location of Japanese Edo period wrecks along the Canadian Pacific Coast. Canadian Journal of Archaeology 27:62-82.

Callaghan, R.T. and S.M. Fitzpatrick 2007. On the relative isolation of a Micronesian archipelago during the historic period: the Palau case study. International Journal of Nautical Archaeology 36:353-364.

Callaghan, R.T. and S.M. Fitzpatrick 2008. Examining prehistoric migration patterns in the Palauan archipelago, western Micronesia: A Computer Simulated Analysis of Drift Voyaging. Asian Perspectives 47:28-44.

Clark, C.D., S.M. Garrod and M. Parker Pearson 1998. Landscape archaeology and remote sensing in southern Madagascar. African Archaeological Review 19:1461-1477.

Dahl, O.C. 1951. Malgache et Maanyan: Une comparision linguistique. Oslo: Egede Institutett.

Dahl, O.C. 1977. La subdivision de la famille Barito et la place du Malgache. Acta Orientalia 34:77-134.

Dening, G.M. 1963. The geographical knowledge of the Polynesians and the nature of inter-island contact, Polynesian Navigation. J. Golson (ed), Polynesian Society Memoir No. 34:138-153.

Dewar, R.E. 1997. Does it matter that Madagascar is an island? Human Ecology 25:481-489.

Dewar, R.E. 1995. Of nets and trees: untangling the reticulate and dendritic in Madagascar's prehistory. World Archaeology 26:301-318.

Dewar, R.E. and T.W. Henry 1993. The culture history of Madagascar. Journal of World Prehistory 7:417-466.

Heikell, R. 1999. Indian Ocean Cruising Guide. St. Ives Cambridgeshire: Imray Laurie Norie and Wilson Ltd.

Hingston, M., S.M. Goodman, J.U. Ganzhorn and S. Sommer 2005. Reconstruction of the colonization of southern Madagascar by introduced Rattus rattus. Journal of Biogeography 32:1549-1559.

Howay, F.W. 1944. Some lengthy open-boat voyages in the Pacific Ocean. American Neptune 4:53-57.

Hurles, M.E., B.C. Sykes, M.A. Jobling and P. Forster 2005. The dual origin of the Malagasy in Island Southeast Asia and East Africa: evidence from maternal and paternal lineages. American Journal of Human Genetics 76:894-901.

Irwin, G. 1992. The Prehistoric Exploration and Colonization of the Pacific. Cambridge: Cambridge University Press.

LeBaron B. R. Jr 1954. Eastern sail affinities, Part II. American Neptune 13:185-211.

Lee, E.C.B. 1965. Survival at Sea. Rome: Centro Internazionale Radio Medico. 
Lee, E.C.B. and K. Lee. 1980. Safety and Survival at Sea. New York: Norton.

Levison, M., R.G. Ward and J.W. Webb. 1973. The Settlement of Polynesia, a Computer Simulation. Canberra: Australian University Press.

Lewis, D. 1972. We, the Navigators. Honolulu: University of Hawaii Press.

McCance, R.A., C.C. Ungley, J.W.L. Crosfill and E.M. Widdowson 1956. The Hazards to Men Lost at Sea, 1940-44. Medical Research Council Special Report No. 291. London: Medical Research Council.

McGrail, S.. 2001. Boats of the World: From the Stone Age to Medieval Times. Oxford: Oxford University Press.

Maloney, C. 1980. People of the Maldive Islands. Bombay: Orient Longman.

Montenegro, Á., M.E. Reneé Hetherington and A.J. Weaver 2006. Modelling pre-historic transoceanic crossings into the Americas. Quaternary Science Reviews 25:1323-1338.

Parker Pearson, M. 1997. Close encounters of the worst kind: Malagasy resistance and colonial disasters in Southern Madagascar. World Archaeology 28:393-417.

Pigache, J.P. 1970. La problème anthropobiologique à Madagascar. Taloha 3:175-177.

Romero-Frias, X. 1999. The Maldive Islanders, a Study of an Ancient Ocean Kingdom. Barcelona: Nova Ethnographia Indica.

Schoff, W.H. 1912. The Periplus of the Erythraean Sea. New York: Longmans, Green and Co.

United States Navy 1995. Marine Climatic Atlas of the World. Asheville: National Climatic Data Center. 